\title{
Simple Pleasures, Small Annoyances, and Goal Progress in Daily Life
}

\author{
NICOLE L. MEAD, VANESSA M. PATRICK, MANISSA P. GUNADI, AND WILHELM HOFMANN
}

\begin{abstract}
Despite the explosion of research on goal pursuit, relatively little is known about the shaping of goal progress by the simple experiences that characterize everyday life. Two literatures furnish competing predictions about the relationship between pleasant daily experiences (simple pleasures), unpleasant daily experiences (small annoyances), and day-to-day goal progress. A 6-day experience-sampling study revealed support for the favored integrative account. On a given day, a relatively high number of simple pleasures offset the negative relationship between the number of small annoyances and goal progress through a restoration of daily happiness rather than a reduction of daily stress. This study highlights the bright side of pleasurable experiences, indicating that goal progress can flourish in a life punctuated with frequent simple pleasures because they help offset daily irritations. As natural precursors to positive and negative affect, simple pleasures and small annoyances could be powerful predictors of important consumer outcomes.
\end{abstract}

$\Lambda$ successful and fulfilling life depends on making progress toward one's daily goals. The vast amount of research devoted to the study of goal pursuit is reflective of the importance of goal progress in consumer behavior (for a review, see Laran 2016). Although that research has greatly advanced the field's knowledge about the proximal factors that shape goal pursuit, relatively less is known about the shaping of goal progress by the pleasant and unpleasant experiences that characterize everyday life. The current investigation sought to address that gap by examining the relationship between simple pleasures, small annoyances, and goal progress in daily life.

Simple pleasures were conceptualized as brief positive experiences that emerge in everyday settings and are readily accessible to most individuals at little or no cost. Examples include watching a funny movie, having a cocktail at the end of a long day, or looking at the stars on a warm summer evening. Small annoyances are the negative counterparts to simple pleasures, instigating irritation instead of happiness. Examples include a traffic jam during the commute to work, a perpetually rainy day, or needing to make an important phone call only to find one's smartphone battery is dead.
We entertained two possible predictions about the relationship between simple pleasures, small annoyances, and goal progress. Theoretically, positive feelings are key to a successful life because they generate the very psychological resources that are necessary for coping with adverse life circumstances (e.g., Fredrickson and Levenson 1998; Folkman and Moskowitz 2000). In controlled laboratory settings, positive emotion offset the detrimental consequences of negative emotion (e.g., Fredrickson and Levenson 1998; Trope, Ferguson, and Raghunathan 2000) and restored selfregulation after ego depletion (Tice et al. 2007). Given that simple pleasures and small annoyances were expected to generate positive and negative feelings, respectively, one possible prediction is that simple pleasures may offset the potentially adverse consequences of small annoyances for goal progress through a restoration of happiness.

Despite the appeal of the buffering theory, research on daily experiences has found little evidence in support of the notion that pleasant daily events can offset the costs of unpleasant daily events (e.g., Lazarus 1984; David et al. 1997). Instead, the daily experiences literature suggests that pleasant and unpleasant daily events are independently rather

Nicole Mead (nicole.l.mead@gmail.com), the corresponding author, was associate professor of marketing, Department of Marketing Management, Rotterdam School of Management, Erasmus University, 50 Burgemeester Oudlaan, 3062PA Rotterdam, the Netherlands; she is now associate professor of marketing, University of Melbourne. Vanessa M. Patrick (vpatrick@bauer.uh.edu) is professor of marketing, Bauer School of Business, University of Houston. Manissa P. Gunadi (gunadi@rsm.nl) is a doctoral student in marketing, Rotterdam School of Management, Erasmus University. Wilhelm Hofmann (wilhelm.hofmann@uni-koeln.de) is a professor of social and economic psychology, Social Cognition Center Cologne, University of Cologne. The authors thank the editor and reviewers for their invaluable feedback. This research was supported by the Erasmus Institute for Research in Management.

JACR, volume 1, number 4. Published online August 29, 2016. http://dx.doi.org/10.1086/688287

(C) 2016 the Association for Consumer Research. All rights reserved. 2378-1815/2016/0104-0011\$10.00 
interactively related to adaptive life outcomes. More specifically, that literature has documented an asymmetric pattern whereby unpleasant daily events are related to both positive and negative outcomes, whereas pleasant daily events are related primarily to positive outcomes. For example, unpleasant daily outcomes contribute to both positive and negative mood in the expected direction, whereas pleasant daily events contribute only to positive mood (e.g., David et al. 1997). Assuming that goal progress is a positive outcome, the daily experiences literature suggests that simple pleasures may be positively associated with goal pursuit, whereas small annoyances may be negatively associated with goal pursuit, but that simple pleasures would not buffer the negative relationship between small annoyances and goal progress.

Although the mood and daily experiences literatures furnish two different predictions, conceptual and methodological limitations of research on daily experiences (reviewed in the next section) may have masked the buffering potential of pleasant daily events. The current work attempted to address those limitations to test the favored integrative prediction that a relatively high frequency of simple pleasures buffers the damaging relationship between small annoyances and goal progress through a restoration of positive well-being. The integrative hypothesis was evaluated in a 6-day experience-sampling study. This methodology enabled us to capture naturalistic simple pleasures and small annoyances temporally close to when they occurred in daily life and to link those experiences to the daily outcomes of well-being and goal progress. The benefits of this methodology, as compared to correlational and diary studies, have been extolled by previous researchers (Csikszentmihalyi and Larson 1987; Hofmann et al. 2012; Mehl and Conner 2012, 2014).

Daily experiences shape consequential outcomes, such as job performance (Ivancevich 1986), psychological health (DeLongis et al. 1982), and physical health (Kanner et al. 1981), and yet the systematic study of daily experiences in the consumer domain is minimal, if existent at all. Because simple pleasures and small annoyances are natural precursors to positive and negative affect, the study of daily experiences may enable researchers to study pleasure and important consumer outcomes in a relatively more naturalistic manner (Alba and Williams 2013).

The current research contributes to the daily experiences literature by studying an unexamined but consequential outcome: goal progress. By integrating the daily experiences, mood, and goal literatures, we identified an outcome for which a relatively high frequency of pleasant daily events may offset the detrimental consequences of unpleasant daily events. To our knowledge, this may be one of the few studies to support the long hypothesized, but sparsely supported, buffering effect of positive daily events. Finally, this research sheds light on the drivers of happiness (e.g., the genetically determined "set-point"; see Lyubomirsky, Sheldon, and Schkade 2005) to present the idea that naturally occurring simple pleasures might contribute to the frequent experience of positive affect, and, consequently, to a happy and successful life.

\section{DAILY EXPERIENCES AND}

\section{ADAPTIVE OUTCOMES}

The study of daily experiences has its roots in the examination of daily hassles and uplifts (e.g., Lazarus, Kanner, and Folkman 1980; Kanner et al. 1981; Stone and Neale 1982). That research was motivated by the theory that, as compared to major life events, daily experiences would be better predictors of adaptive outcomes because the latter are proximal manifestations of the former. That research hypothesis bore fruit. A robust negative relationship between daily hassles and adaptive outcomes was found across a wide range of investigations, with hassles outpredicting major life events (e.g., Kanner et al. 1981; DeLongis et al. 1982; Monroe 1983; DeLongis, Folkman, and Lazarus 1988; Bolger et al. 1989).

The study of daily uplifts was more challenging, however. Initially, uplifts were theorized to be important for coping with adverse life circumstances (e.g., Lazarus et al. 1980). Yet scant evidence for the buffering effect of positive daily events was found (e.g., Lazarus 1984; David et al. 1997). Instead, researchers puzzled over three different, and sometimes conflicting, patterns between uplifts and adaptive outcomes: a positive relationship (Ivancevich 1986; Kanner et al. 1987), no relationship (Kanner et al. 1981; DeLongis et al. 1982; Monroe 1983), or a counterintuitive negative relationship (Kanner et al. 1981; DeLongis et al. 1982).

Because of the robust predictive power of hassles and because of the equivocal nature of uplifts, many researchers abandoned the study of uplifts and began to focus exclusively on hassles (DeLongis et al. 1988; Bolger et al. 1989; see also Folkman and Moskowitz 2000). The pattern for uplifts becomes clear when considered through the theoretical lens that bad events exert a stronger influence over outcomes than do good events (Baumeister et al. 2001; see also Taylor 1991). Indeed, uplifts were associated with positive outcomes such as job performance (Ivancevich 1986), social competence (Kanner et al. 1987), and positive mood (Kanner et al. 1981; Stone 1987; Langston 1994; David et al. 
1997), but they were not associated with negative outcomes such as psychological and physical health (Kanner et al. 1981; DeLongis et al. 1982; compare Kanner et al. 1987). In contrast, because of the greater power of bad compared to good, unpleasant daily events evinced robust relationships with positive (e.g., Stone 1987; Repetti 1993) and negative outcomes (e.g., Kanner et al. 1987; Bolger et al. 1989; David et al. 1997).

Taken together, the daily experiences literature suggests that positive daily events are associated with good outcomes but they may not be powerful enough to offset the bad things that happen in life. Concluding that positive daily events are not potent enough to offset negative daily events may be a conclusion drawn too soon, however. Conceptual and methodological limitations of previous research may have masked the buffering potential of uplifts.

Conceptually, the study of daily hassles encapsulated both discrete (e.g., losing one's keys) and chronic events (e.g., concerns about health in general), whereas daily uplifts merely captured discrete events (e.g., receiving a hug from a loved one). In this way, daily hassles conflated individual differences in psychological functioning with daily annoyances, which could have resulted in an overestimation of the contribution of bad events for predicted outcomes. Put simply, it may have been an unfair match, and the heft of the hassles measure may have masked the buffering potential of uplifts.

In addition to the conceptual discrepancy between uplifts and hassles, prior investigations may have been constrained by available methodological and analytic tools. The majority of the daily experiences literature assessed daily experiences with a researcher-generated inventory that was completed every month or every evening. Because positive emotions fade more quickly and easily than negative emotions, positive emotions need to be captured soon after they occur (Thomas and Diener 1990). Applying this insight to the daily experiences literature, previous studies may have underestimated the predictive power of pleasant events. In addition, data analytic tools were sometimes insufficient for detecting a possible interaction between pleasant and unpleasant daily events.

The current research sought to build on the daily experiences research in the following ways. (i) We introduce simple pleasures and small annoyances, which depart from uplifts and hassles because the former capture discrete daily events as identified by the participant rather than the researcher. Although we still anticipated an asymmetric influence of pleasant and unpleasant daily events, restricting the investigation of pleasures and annoyances to discrete events enabled a relatively fair comparison between the two types of events. (ii) We assessed pleasures and annoyances temporally close to when they occurred (within 30 minutes) to minimize the chance that positive experiences would fade from respondents' memory. In this way, we increased the chance of finding a buffering pattern should one exist. (iii) We assessed the interplay between pleasures and annoyances using data analytic techniques that enabled detection of a buffering pattern should one exist. (iv) We investigated a positive outcome: making progress on one's goals. As mentioned, pleasant events tend to affect positive outcomes but not negative outcomes, so a possible buffering pattern is most likely to be found for a positive outcome. By implementing these conceptual and methodological developments, we sought to test the long-theorized but little-found buffering possibility of positive daily experiences.

\section{AFFECT AND GOAL PROGRESS}

Simple pleasures and small annoyances were expected to imbue daily life with positive and negative feelings, respectively. Given the rich interplay between affect and goal progress, we turned to an examination of that literature to further evaluate the possible relationship between simple pleasures, small annoyances, and goal progress.

Positive affect is a central aspect of daily life and is considered one of the three distinct pathways toward wellbeing (the other two being engagement and meaning; Seligman 2000). The experience of mild positive affect serves as a signal that one is in a benign yet desirable environment (Cantor et al. 1991; Carver and Scheier 1998; Clore et al. 2001). This state, in which people feel free of danger and impending loss, promotes resource building (Lyubormirsky 2001), involvement with approach goals (Elliot and Thrash 2002), and alignment with long-term goals rather than competing short-term outcomes (Trope and Neter 1994; Trope and Fishbach 2000; Trope et al. 2000), all of which are crucial for effective goal pursuit.

Positive feelings may be particularly beneficial when life throws people curveballs. The adaptive function of positive affect may be its ability to build social and intellectual resources (Fredrickson 1998), the very resources that are eroded by negative events but which are crucial for sustained goal pursuit. In the domain of self-regulation, positive affect has been found to buffer the detrimental consequences of negative mood on information processing (Raghunathan and Trope 2002) and to restore self-control after ego depletion (Tice et al. 2007). 
In summary, positive feelings can renew the very resources that are eroded by negative feelings but which are required for goal pursuit. If simple pleasures and small annoyances infuse life with positive and negative feelings, respectively, then the happiness instilled by simple pleasures may help offset the negative consequences of small annoyances for goal pursuit.

\section{THE PRESENT INVESTIGATION}

The current research tested the favored integrative prediction that experiencing a relatively high number of simple pleasures on a given day buffers the adverse relationship between small annoyances and goal progress. We predicted that the buffering pattern would be explained by a restoration of positive well-being rather than through a reduction in negative well-being. To test those predictions, we conducted an experience-sampling study, which is described next.

\section{METHOD AND PROCEDURE Sample}

We aimed to collect repeated data from at least 100 participants, as power in experience-sampling research is both a function of the number of participants (level 2) and the number of repeated observations within those participants (level 1). The target sample size is consistent with previous research on daily experiences (e.g., Kanner et al. 1981; David et al. 1997). At the end of the recruitment period (the academic year), 122 students and employees $(56.6 \% \mathrm{fe}-$ male; 18 to 48 years, $M=22.68, \mathrm{SD}=3.41$ ) from Erasmus University and its surrounding city (Rotterdam, the Netherlands) had been recruited to participate. Participants completed the study in exchange for personal feedback and the chance to win a tablet computer.

The majority of participants were Caucasian (68.9\%; Asian $=19.7 \%$; Other $=9.0 \%$; Hispanic $=1.6 \%$; African American $=0.8 \%)$ and single (86.1\%; cohabiting $=12.3 \%$; $1.6 \%=$ married). Social economic status (SES) was measured using the MacArthur 10-rung ladder of subjective social status (1st rung $=$ worst off in your country to 10th rung = best off in your country; Goodman et al. 2001); on average, the sample reported feeling middle class (range $=$ 1 to $9 ; M=4.15$, SD $=1.46$ ).

\section{Overview of Study}

Participants registered for the study online. At that time, they provided demographics (reported above) and verified their smartphone with the company SurveySignal. SurveySignal is a web-based system that supports the dis- tribution of "signals" to participants in the form of text messages (Hofmann and Patel 2015). Each daily signal contains a clickable individualized hyperlink, which, when clicked, directs participants to a survey page on their smartphones' Web browser.

After registration, participants were given instructions about the types of daily experiences they should report in the study. Simple pleasures were described as "positive experiences that are readily available to most people, cost very little, and are fleeting or short in duration." Small annoyances were defined as "minor hassles or interruptions in one's daily life that could bring about feelings of irritation." Participants were informed that such experiences are highly personal and that they should report what they personally consider pleasures or annoyances. They were asked not to report other types of events (e.g., major life events) in the study.

To minimize the possibility that the predictors - simple pleasures and small annoyances - would lead to carryover effects on the outcomes of interest - goal progress and wellbeing - the predictor and outcome measures were assessed at separate points in the day. Specifically, simple pleasures and small annoyances were captured five times during the day for 6 consecutive days (see the "Momentary Assessment" section), whereas goal progress and well-being were assessed during each of the 6 evenings (see the "Nightly Diary" section). The temporal order of the measurements-experiences during the day and outcomes in the evening - enabled a test of the hypothesized process model.

For all 36 signals distributed during the course of the study, SurveySignal emitted a reminder signal if a response had not been received 15 minutes after the initial signal had been sent. Participants were encouraged to respond as soon as possible and to respond as accurately as possible. Each survey link sent in the signal was valid for a maximum of 3 hours; after this time, participants could not complete the survey. Each survey could be completed only once per participant for each measurement occasion.

The median response rate for the entire sample was $72.2 \%$ (i.e., completing 26 of the 36 surveys). This response rate is comparable with published experience-sampling studies (e.g., Hofmann et al. 2014; Hofmann, Finkel, and Fitzsimons 2015).

\section{Mobile Phase}

Momentary Assessments. Starting the day after registration, participants received five daily signals between 9 a.m. and 8 p.m. for 6 consecutive days. This time frame was di- 
vided into five blocks of 132 minutes; one signal was sent at a random time within each block (Hektner, Schmidt, and Csikszentmihalyi 2006). Signals were programmed to be at least 1 hour apart to minimize the intrusiveness of the signals.

In each momentary assessment, participants indicated whether they had experienced a simple pleasure, a small annoyance, or neither within the past 30 minutes. If participants experienced both a pleasure and an annoyance, they were asked to report the most recent experience. The 30-minute window was implemented to ensure accurate, high-quality responses.

For each pleasure or annoyance, participants were asked to describe the experience in a sentence or two as though they were telling it to their best friend. They did this by typing the experience into a text box in the survey. Participants could skip the description section and still continue with the remainder of the momentary assessment. The descriptions tended to be quite short as evidenced by the average character count for all reported experiences $(M=$ 73.48 characters, $S D=63.60$ ). Participants were asked to provide a description so we could compare reported experiences with our conceptualization of simple pleasures and small annoyances (see the "Coding" section for more details).

Simple pleasures and small annoyances were characterized as being relatively fleeting. To check that assumption, participants indicated the length of the experience $(1=$ still ongoing, $2=$ less than 5 minutes, $3=5-10$ minutes, $4=$ 10-15 minutes, $5=20-30$ minutes, $6=$ more than $30 \mathrm{~min}$ utes). Removing experiences that were still ongoing (i.e., received a rating of 1 ), simple pleasures and small annoyances were reported to last on average between 5 and 10 minutes long. Simple pleasures and small annoyances were similar in duration $(B=.060, \mathrm{SE}=.100, p=.549)$.

Morning Diary. In the first daily assessment, participants indicated which goal(s) they wished to make progress on during that day. Participants were presented with goal categories drawn from previous research (professional, exercise, social, leisure, maintenance, or self-defined other). They were asked to rate how much progress they wanted to make on each of the goals during the day ( $0=$ not today, $1=$ a bit of progress, 2 = some progress, 3 = a lot of progress). Participants could pursue as many or as few goals as they desired.

Nightly Diary. Every evening for 6 consecutive evenings, participants received a nightly diary signal at 9 p.m. (local time). Participants rated their progress for each goal they planned to work on that day (i.e., those that received a rating of greater than 0 during the morning diary). For each goal, participants rated how much progress they made on that goal during the day as compared to their desired goal progress $(-3=$ much less progress than expected to $+3=$ much more progress than expected). Participants did not view or rate goal progress for those goals that received a rating of 0 during the morning survey.

To measure well-being, we adapted measures from Campbell, Converse, and Rodgers (1976). To measure daily positive well-being, participants rated how happy they were $(-3=$ very unhappy to $3=$ very happy; $M=1.00, \mathrm{SD}=$ 1.22). To measure daily negative well-being, participants rated how stressful they found the day and how mentally exhausting they found the day (each using $0=$ not at all to 6 = very). The two measures of negative well-being were correlated, $r(408)=.521, p<.001$, so they were averaged to form an index of daily negative well-being ( $\alpha=.69 ; M=$ $2.54, \mathrm{SD}=1.40$ )

\section{Coding of Participant-Generated Experiences}

Two research assistants who were blind to the purpose and hypotheses of the investigation coded the descriptions of the experiences following a coding scheme. One research assistant coded all responses; a second research assistant coded $25 \%$ of the responses to determine interrater agreement, which was good (kappa $=.71$ ). Coding was used to check that reported experiences were consistent with our conceptualization of simple pleasures and small annoyances. It also enabled a characterization of the nature of daily experiences.

Experience Domains. Twenty-three domains were identified by coders (see fig. 1 for domains and domain frequencies for all reported experiences). Domain coding enabled an assessment of the hypothesized distinctions between the constructs of simple pleasures/small annoyances and uplifts/hassles. First, whereas the hassles/uplifts measures captured chronic and discrete events (Lazarus 1984), small annoyances/simple pleasures were primarily discrete events (97.4\% of experiences). Second, because hassles were conceptually distinct from small annoyances, only 14 of the 23 (60.8\%) small annoyance domains were captured by the hassles measure (Kanner et al. 1981). As expected, there was a fair degree of overlap between simple pleasures and uplifts, with 21 of the 23 domains being captured by the uplifts measure (91.3\%). 


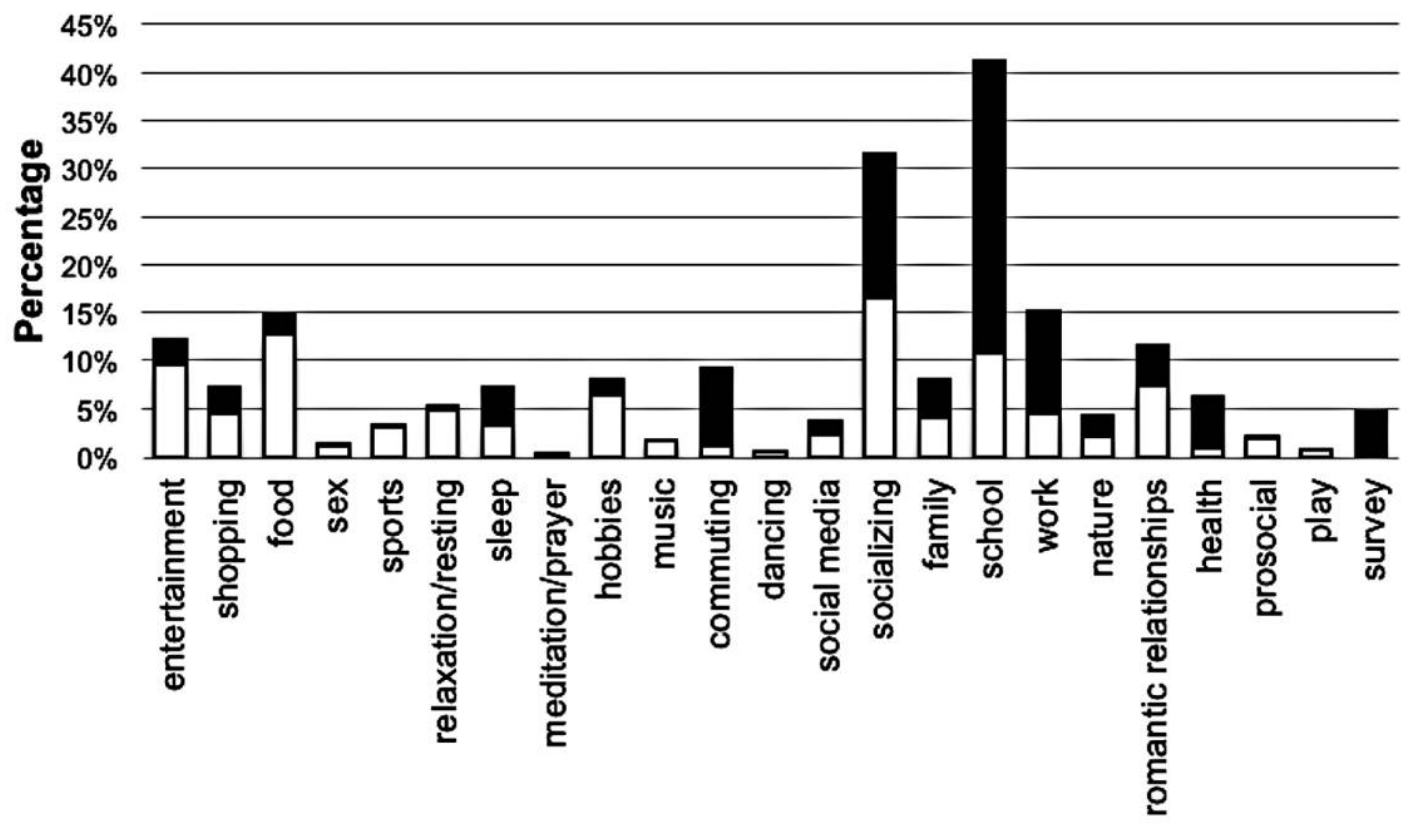

Domains

\section{口Simple Pleasure Small Annoyance}

Figure 1. Distribution of the domains of reported experiences. Percentage reflects proportion of the total reported experiences coming from each domain.

Ordinary versus Extraordinary Experiences. The coders checked whether participants were indeed reporting ordinary instead of extraordinary experiences. Ordinary experiences were defined as common occurrences that happen frequently in one's everyday life, whereas extraordinary experiences are rare, more remarkable events (Bhattacharjee and Mogilner 2014). Each experience was classified by coders as ordinary or extraordinary ( $1=$ ordinary, $2=$ extraordinary). Only one experience, less than $.001 \%$ of all reported experiences, was coded as an extraordinary experience. Hence, participants followed the instructions from the study, reporting relatively mundane ordinary experiences that were either enjoyable or annoying.

\section{RESULTS}

In total, participants reported 2,460 unique experiences. On average, across days, respondents reported experiencing more simple pleasures $(M=1.83, \mathrm{SD}=.95$; range 0 to 6$)$ than small annoyances $(M=.95, \mathrm{SD}=.92$; range 0 to 5$), t(1,128)=17.630, p<.001$. The greater frequency of simple pleasures to small annoyances is consistent with previous studies examining uplifts and hassles among middle-age adult populations (e.g., Kanner et al. 1981; DeLongis et al. 1982; Ivancevich 1986).

Our hypotheses were tested using multilevel modeling (e.g., Hox 2010) in order to take into account the nested nature of the data (i.e., repeated measures within persons). The continuous predictors of the number of simple pleasures and small annoyances experienced on a given day were person-mean centered in order to estimate the unbiased strength of relationships at level 1 (Enders and Tofighi 2007). Person-centered continuous predictors of daily simple pleasures and small annoyances revealed a distribution that approximated normality $\left(M_{\mathrm{SP}}=0.00, \mathrm{SD}=.87\right.$, range -2.17 to $4.00 ; M_{\mathrm{SA}}=0.00, \mathrm{SD}=.70$, range -1.86 to 3.91 ). Using person-centered predictors enables us to estimate variation around a respondent's mean rather than the sample mean.

For ease of interpretation, the predictors were not log transformed. Sensitivity analyses indicated that log-transformed person-centered predictors yielded descriptively similar results as analyses using untransformed person-centered predictors. 


\section{Daily Goal Progress}

We first tested the favored, integrative prediction that experiencing a relatively high number of simple pleasures on a given day would offset the hypothesized negative relationship between small annoyances and goal progress for that same day. The number of simple pleasures and small annoyances on a given day (both person centered) and the interaction between the two were entered as fixed predictors in a multilevel model predicting daily goal progress. In this way, the model estimated conditional effects for each predictor (simple pleasures, small annoyances) at personcentered mean levels of the other predictor (small annoyances, simple pleasures). The outcome measure of daily goal progress was computed by averaging goal progress across all goal categories assessed during a given day.

As predicted, the model revealed that the number of simple pleasures experienced during a given day was positively related to goal progress on that same day $(B=.131$, $\mathrm{SE}=.054, p=.016)$. The anticipated interaction between simple pleasures and small annoyances was marginally significant $(B=.124, \mathrm{SE}=.073, p=.087$; see fig. 2$)$. In this model, which represents the conditional effect of small annoyances at the mean value of simple pleasures, there was no overall relationship between small annoyances and goal progress $(p=.328)$.

To dissect the interaction between simple pleasures and small annoyances, we examined the relationship between small annoyances and goal progress at relatively high and low frequencies of simple pleasures (i.e., one SD above and below the person-centered mean; Aiken and West 1991).

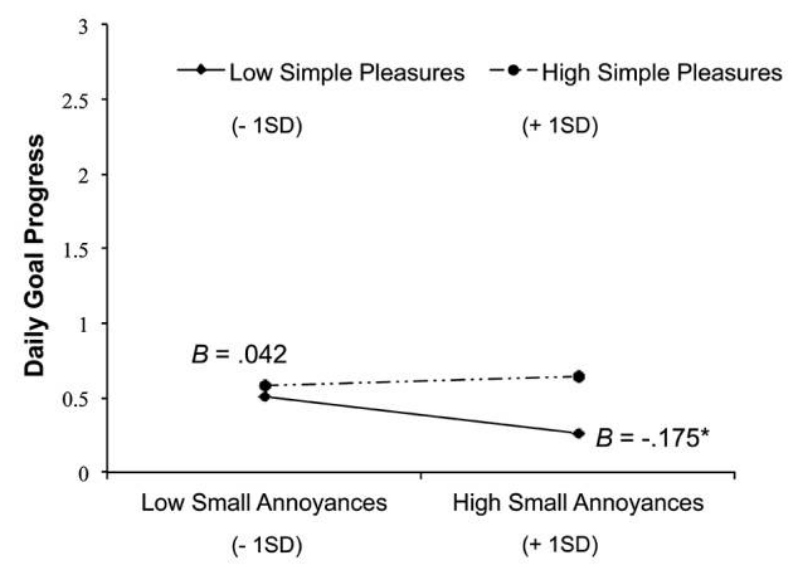

Figure 2. The interaction between the number of (person-centered) simple pleasures on a given day and the number of (personcentered) small annoyances on a given day when predicting daily goal progress. ${ }^{*} p=.043$.
When the number of simple pleasures was relatively low on a given day, the number of small annoyances experienced during that same day was negatively related with goal progress during that day $(B=-.175, \mathrm{SE}=.086, p=.043)$. When simple pleasures were relatively high on a given day, the number of small annoyances reported by the respondent during that day was not predictive of daily goal progress $(B=.042$, $\mathrm{SE}=.099, p=.670$ ).

Looked at a different way, when there was a relatively high frequency of small annoyances on a given day, there was a positive relationship between the number of simple pleasures experienced on a given day and goal progress during that same day $(B=.218, \mathrm{SE}=.084, p=.010)$. In contrast, when participants experienced relatively few small annoyances on a given day, the number of simple pleasures experienced during the day was not related to overall goal progress for that same day $(B=.043, \mathrm{SE}=.063, p=.492)$. Hence, the pattern of results was supportive of a buffering pattern.

\section{Daily Well-Being}

Daily Happiness. We hypothesized that simple pleasures and small annoyances infuse the day with bursts of positive and negative feelings, respectively. Because bad is stronger than good (Baumeister et al. 2001), we expected that a relatively high number of simple pleasures would statistically offset a negative relationship between small annoyances and positive well-being but that no such buffering pattern would be found for negative well-being. We therefore ran multilevel models in which we predicted daily happiness and negative well-being from the predictive model that was used to assess daily goal progress.

Predicting daily happiness, the model revealed a negative association between the number of small annoyances experienced on a given day and happiness experienced on that same day $(B=-.192$, SE $=.076, p=.012)$. Hence, the more annoyances experienced on a given day, the less happy participants reported being on that same day. The negative relationship between annoyances and happiness was qualified by an interaction between the number of simple pleasures and the number of small annoyances experienced on a given day $(B=.197, \mathrm{SE}=.085, p=.020$; see fig. 3). At average levels of small annoyances, there was no relationship between simple pleasures and daily happiness $(B=.086, \mathrm{SE}=.061, p=.160)$.

Dissecting the interaction between simple pleasures and small annoyances revealed a pattern that was similar to the pattern obtained for goal progress. When simple pleasures 


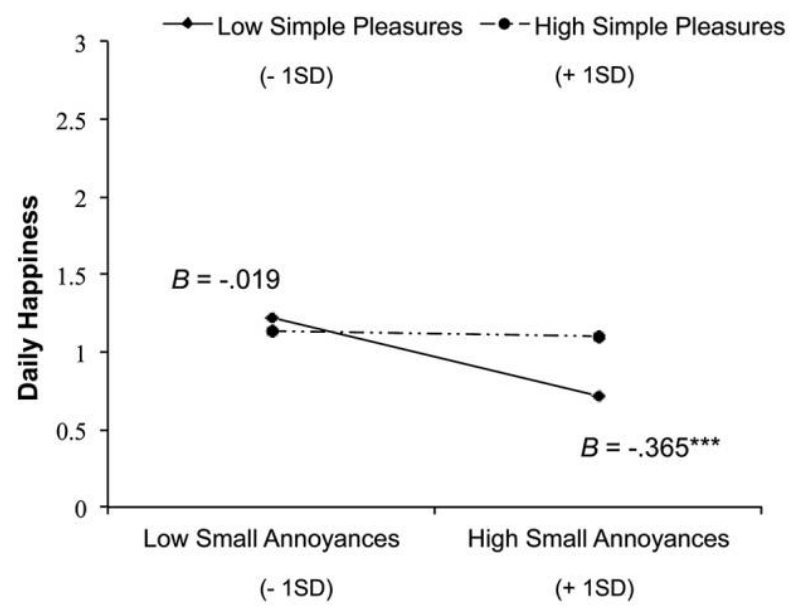

Figure 3. The interaction between the number of (person-centered) simple pleasures on a given day and the number of (personcentered) small annoyances on a given day, predicting overall happiness during the day. ${ }^{* * *} p<.001$.

were relatively infrequent on a given day, the number of small annoyances experienced that day was negatively related with daily happiness $(B=-.365, \mathrm{SE}=.097, p<$ .001). In line with hypotheses, when simple pleasures were relatively frequent on a given day, the number of small annoyances experienced during that day was not associated with daily happiness $(B=-.019, \mathrm{SE}=.114, p=.865)$. In other words, results were supportive of a buffering pattern: small annoyances were negatively related to happiness on days when simple pleasures where relatively scarce, but they were not related to daily happiness on days when simple pleasures were plentiful.

Looked at a different way, when small annoyances were relatively frequent on a given day, there was a positive relationship between the number of simple pleasures experienced during that day and daily happiness $(B=.225$, SE $=$ .096, $p=.019$ ). In contrast, when small annoyances were relatively infrequent on a given day, simple pleasures were not related to daily happiness $(B=-.053, \mathrm{SE}=.074$, $p=.476)$.

Negative Well-Being. Predicting negative well-being (i.e., the index of exhaustion and stress), the model revealed a positive association between the number of small annoyances experienced on a given day and daily negative wellbeing $(B=.454, \mathrm{SE}=.086, p<.001)$. In other words, at mean levels of simple pleasures, small annoyances were positively associated with negative well-being. The conditional relationship between simple pleasures and negative well- being at mean level of small annoyances was not significant $(p=.843)$ nor was the interaction term $(p=.885)$.

Summary. The pattern of results for well-being was consistent with the theory that bad is stronger than good (e.g., Baumeister et al. 2001) and previous research on daily experiences and mood (David et al. 1997; Major et al. 1997). Simple pleasures only contributed to positive well-being, whereas small annoyances contributed to positive and negative well-being. These results suggest that if simple pleasures buffer the negative relationship between small annoyances and goal progress through their association with daily mood, it is most likely through happiness and not negative well-being.

\section{Process Analyses}

Next we tested the hypothesis that experiencing a relatively high number of simple pleasures offsets the negative relationship between small annoyances and daily goal progress through a restoration of positive well-being. Because SPSS cannot estimate indirect effects for multilevel models, the indirect effect was assessed using Mplus. Our theoretical framework called for mediated moderation which was tested with three models (Müller, Judd, and Yzerbyt 2005) in Mplus.

The first model replicated the previously reported interactive effect of simple pleasures and small annoyances on the dependent variable of daily goal progress $(B=.128$, $\mathrm{SE}=.068, p=.061)$. The second model replicated the previously reported interactive effect of simple pleasures and small annoyances on the proposed mediator-daily happiness $(B=.281, \mathrm{SE}=.089, p=.002)$. Given that the statistical pattern of the interaction for the putative mediator (happiness) mirrored the pattern for the dependent measure (goal progress), we tested the third model, in which we added the putative mediator to the original model predicting goal progress. When the proposed mediator (happiness) was added to the original model, happiness remained a significant predictor of goal progress $(B=.362, \mathrm{SE}=.036, p<.0001)$, whereas the interaction between simple pleasures and small annoyances was driven far from significance $(B=.027, \mathrm{SE}=$ $.065, p=.685$; see fig. 4). The estimated indirect effect from the simple pleasures $\times$ small annoyances interaction via happiness was significant $(B=.102, \mathrm{SE}=.035, p<.001)$. These results support the possibility that simple pleasures offset the negative association between small annoyances and goal pursuit through a restoration of the happiness that was eroded by small annoyances. 


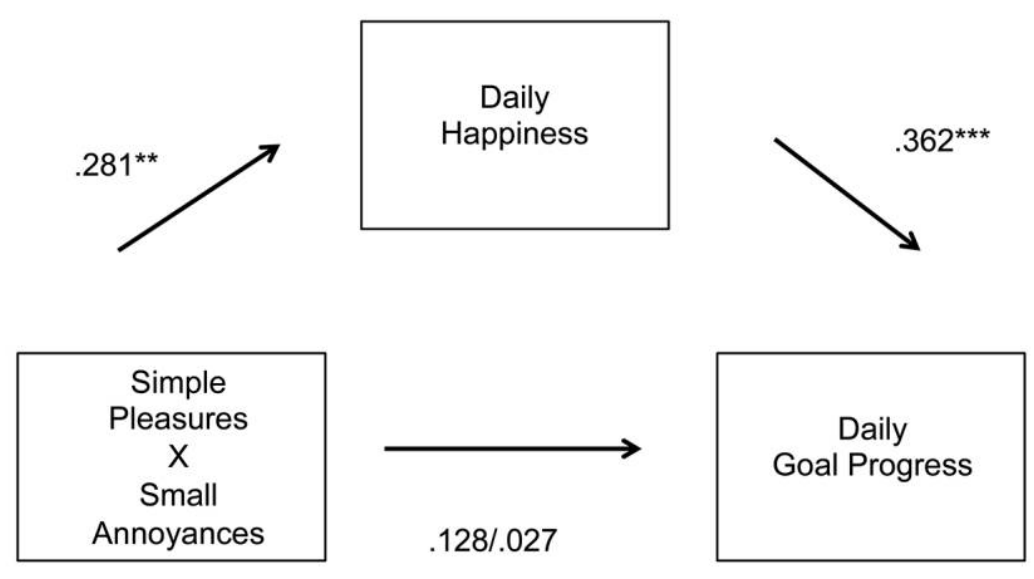

Figure 4. The interaction between the number of simple pleasures and the number of small annoyances experienced on a given day on goal progress for that same day was mediated by participants' daily happiness. Numbers refer to standardized betas. ${ }^{* *} p<.01 ;{ }^{* * *} p<.001$.

\section{Robustness Checks}

An alternative possibility for the reported effects is that simple pleasures and small annoyances were conflated with actual goal progress. This is in contrast to the proposed theory that simple pleasures and small annoyances instigate affective reactions that have downstream consequences for goal progress. A design feature of the study casts doubt on the alternative account, namely, the separated measurement of experiences and outcome. Nevertheless, we investigated the validity of the alternative account by conducting robustness checks.

Experiences as Goal Achievement. Each reported experience was coded by research assistants for the degree to which the experience was an achievement of a goal ( $1=$ not at all to $5=$ very much so), with the seven possible achievements being academic, health, work, interpersonal, materialistic, financial, or personal growth achievement $(1=$ yes, 2 = no). Goal achievement was represented in each analysis via a set of 6 effects-coded variables using the base domain of least interest (i.e., the "financial achievement" category). Effects coding was chosen over dummy coding because the former enabled us to estimate the effects of our focal predictors across the average effect of the domain (control) variable in the model (Cohen et al. 2003).

Controlling for the degree to which each simple pleasure or small annoyance reflected goal achievement, conclusions from the previously reported results did not change. Controlling for coded goal achievement, the positive relationship between simple pleasures and daily goal progress remained significant $(B=.128, \mathrm{SE}=.053, p=.018$ ) and the interaction between small annoyances and simple plea- sures when predicting goal progress remained marginally significant $(B=.126, \mathrm{SE}=.072, p=.081)$. The goal achievement coefficients were not significant predictors of goal progress $(p>.250)$.

Simple slopes analyses controlling for the degree to which the daily experiences reflected goal achievement also replicated previously reported results. Controlling for goal achievement, the model revealed a robust positive relationship between the number of simple pleasures experienced on a given day and daily goal progress at relatively high frequencies of daily small annoyances $(B=.217, \mathrm{SE}=.083$, $p=.010)$. Also replicating the primary results while controlling for goal achievement, simple slopes analyses revealed a negative relationship between the number of daily small annoyances and daily goal progress at relatively high frequencies of simple pleasures $(B=-.175, \mathrm{SE}=.086, p=$ .042). These analyses cast doubt on the alternative possibility that simple pleasures and small annoyances were related to goal progress because the experiences constituted goal achievement.

Domain of Experience. We also examined whether experiences were conflated with goal achievement by controlling for the domain of the experience. This is because some domains may be more strongly linked with goal achievement than others (e.g., work versus entertainment).

To assess this possibility, we first examined whether domain was confounded with pleasure or annoyance (i.e., whether some domains were associated only with pleasures or annoyances). Experience domain was represented via a set of 22 effects-coded variables using the base domain of least interest as the comparison condition (i.e., the "survey" 
category). Analyses suggested that most domains were equally likely to be reported as an annoyance or pleasure (see fig. 1), although consumption of food was more likely to be reported as a pleasure than an annoyance (Cramer's $\mathrm{V}=.242, p=.047$ ), commuting was more likely to be reported as an annoyance than a pleasure (Cramer's $\mathrm{V}=$ $.248, p=.041)$, and school as more annoying than pleasurable (Cramer's $\mathrm{V}=.240, p=.050$ ). The direction of these effects is inconsistent with the alternative explanation that domain of simple pleasure accounts for goal progress (e.g., school was more likely to be reported as an annoyance rather than a pleasure).

We then re-ran our primary analyses while controlling for the 23 domains of experience. Daily goal progress was regressed on the main model (number of simple pleasures, number of small annoyances, and the interaction between simple pleasures and small annoyances) with the addition of the 22 domain codes.

While controlling for domain of experience, the model revealed results that replicated those previously reported: there was a positive relationship between the number of simple pleasures experienced on a given day and daily goal progress $(B=.122, \mathrm{SE}=.056, p=.030)$, which was qualified by a marginal interaction between the number of simple pleasures and small annoyances $(B=.127, \mathrm{SE}=.073$, $p=.083)$. In this model, the domain codes were not significant predictors of goal progress $(p>.112)$, with the exception of prosocial behavior, which was marginally significant $(B=-1.078, \mathrm{SE}=.0646, p=.096)$. The direction of that unpredicted effect is inconsistent with the alternative hypothesis because it indicates that prosocial behaviors, which were primarily reported as a simple pleasure (see fig. 1), were negatively associated with goal progress.

Next, we dissected the interaction between simple pleasures and small annoyances predicting goal progress while controlling for domain of simple pleasures and small annoyances. Again, the simple slopes analyses controlling for experience domain yielded results descriptively similar to the main analyses previously reported. Controlling for domains, there was a positive relationship between the number of simple pleasures and daily goal progress at high frequencies of small annoyances $(B=.211, \mathrm{SE}=.085, p=$ .014) and a negative relationship between the number of small annoyances and daily goal progress at low frequencies of simple pleasures $(B=-.200, \mathrm{SE}=.089, p=.026)$. Hence, results for goal progress were conceptually similar when controlling for the domain of simple pleasures and annoyances.

\section{DISCUSSION}

A 6-day experience-sampling study tested competing predictions about the shaping of goal progress by the simple pleasures and small annoyances that characterize everyday life. Because simple pleasures and small annoyances were hypothesized to imbue daily life with positive and negative affect, respectively, we predicted that simple pleasures would buffer the detrimental consequences of small annoyances for daily goal progress. Results supported that prediction. Respondents' daily goal progress appeared to suffer on days that were characterized by a relatively high number of small annoyances but relatively few simple pleasures. However, on days when respondents reported experiencing a relatively high number of simple pleasures, small annoyances did not appear to hinder goal progress.

When scholars began studying daily experiences, in the form of uplifts and hassles, they hypothesized that pleasant daily experiences would offset the harmful consequences of unpleasant daily experiences (Lazarus et al. 1980). Yet most investigations failed to find evidence in support of the buffering hypothesis (e.g., Lazarus 1984; David et al. 1997). The results of the current study may have diverged from previous research for a few reasons. First, the investigation focused on an outcome - goal progress - that relies heavily on positive affect, the downstream affective reaction to pleasant daily events. Second, the introduced constructs of simple pleasures and small annoyances were updated conceptualizations of uplifts and hassles. By conceptualizing pleasurable and irritating experiences as (a) discrete events only, not chronic events, and $(b)$ experiences that were respondent identified instead of researcher identified, our study may have provided a relatively more sensitive test of the buffering hypothesis. Third, as compared to monthly or nightly surveys of daily hassles and uplifts, the experience-sampling methodology maximizes the chance of detecting a positive experience before it fades from memory.

Controlled experiments in the laboratory are essential for testing causal hypotheses in a precise fashion. Those experiments can be supplemented with experience-sampling studies, in part to help determine a theory's ability to predict behavior in everyday life (e.g., Taquet et al. 2016). By identifying and studying a category of pleasures which respondents experienced as being primarily positive in nature and which served as an energizing force in their daily lives, the current study provides naturalistic evidence for the functional, adaptive benefits of positive affect. In addition, the current study provides a snapshot of what brought our respondents pleasure in their daily lives without im- 
posing boundaries on what does and does not constitute a hedonic pleasure (Alba and Williams 2013).

\section{Limitations and Future Directions}

Although the current study provides novel insight into the shaping of goal progress by daily experiences, there are limitations that warrant mention and provide opportunities for future investigations. One limitation is the nature of our sample, which was composed primarily of university students. Consistent with previous research that examined daily experiences among middle-age adults (Kanner et al. 1981; DeLongis et al. 1982; Ivancevich 1986), the student respondents in the current study reported on average more daily pleasures than daily annoyances. However, as compared to previous generations, current generations of young adults are happier, whereas older adults are less happy (Twenge, Sherman, and Lyubomirsky 2015). In this way, it remains an empirical question whether the buffering pattern observed in the current work would also be observed among respondents who experience a relatively higher number of small annoyances, particularly if small annoyances should outnumber simple pleasures on a daily basis. On the other hand, students may have been a conservative sample in which to test our hypotheses given that relatively young people tend to derive more happiness from extraordinary than ordinary experiences (Bhattacharjee and Mogilner 2014).

A second limitation is the correlational nature of our findings. Although the lagged methodology in the current work enabled a test of our hypothesized causal chain, future laboratory work should provide a rigorous, causal test of the buffering hypothesis by manipulating simple pleasures and small annoyances, measuring affective responses, and observing behavioral goal pursuit. Moving beyond the correlational nature of the current study, future experiencesampling work could use manipulations at the time of assessment to implement interventions that may boost goal progress, such as by savoring simple moments.

A third limitation is the lack of identified boundary conditions. Future research could test situational and dispositional parameters of the model presented here. For example, some people may be more disposed to notice and savor simple pleasures, while others might be more predisposed to ruminate on small annoyances. Some categories of simple pleasures may be more beneficial for goal pursuit than others because they inspire people (e.g., a beautiful sunset might be more inspiring than getting green lights all the way to work, although both might be equally plea- surable) or make salient a closely held value (e.g., seeing an old couple hold hands while on their daily walk might remind you of the importance of love and commitment). The question of whether the impact of simple pleasure is similar depending on when it is sought or passively experienced remains to be tested. In the current study, both types of simple pleasures were captured, but it is an empirical question whether one is more consequential than the other.

\section{Concluding Comments}

Human flourishing depends on making progress toward cherished life goals. Although societies, religions, and sometimes even consumer behavior researchers sometimes construe pleasure as a pernicious force that needs to be regulated, the current work suggests that simple pleasures may be imperative for the pursuit of valued life goals, particularly when a person is having a very bad day.

\section{REFERENCES}

Aiken, Leona S., and Stephen G. West (1991), Multiple Regression: Testing and Interpreting Interactions, Thousand Oaks, CA: Sage.

Alba, Joseph W., and Elanor F. Williams (2013), "Pleasure Principles: A Review of Research on Hedonic Consumption," Journal of Consumer Psvchology, 23 (1), 2-18.

Baumeister, Roy F., Ellen Bratslavsky, Catrin Finkenauer, and Kathleen D. Vohs (2001), "Bad Is Stronger than Good," Review of General Psychologv, 5 (4), 323-70.

Bhattacharjee, Amit, and Cassie Mogilner (2014), "Happiness from Ordinary and Extraordinary Experiences," Journal of Consumer Research, 41 (1), 1-17.

Bolger, Niall, Anita DeLongis, Ronald C. Kessler, and Elizabeth A. Schilling (1989), "Effects of Daily Stress on Negative Mood," Journal of Personality and Social Psychologv, 57 (5), 808-18.

Campbell, Angus, Philip E. Converse, and Willard L. Rodgers (1976), The Quality of American Life: Perceptions, Evaluations, and Satisfactions, New York: Russell Sage Foundation.

Cantor, Nancy, Julie Norem, Christopher Langston, Sabrina Zirkel, William Fleeson, and Carol Cook-Flannagan (1991), "Life Tasks and Daily Life Experience," Journal of Personality, 59 (3), 425-51.

Carver, Charles S., and Michael F. Scheier (1998), On the Self-Regulation of Behavior, Cambridge: Cambridge University Press.

Clore, Gerald L., Robert S. Wyer Jr., Bruce Dienes, Karen Gasper, Carol Gohm, and Linda Isbell (2001), "Affective Feelings as Feedback: Some Cognitive Consequences," in Theories of Mood and Cognition: A User's Guidebook, ed. Leonard L. Martin and Gerald L. Clore, Mahwah, NJ: Erlbaum, 27-62.

Cohen, Jacob, Patricia Cohen, Stephen G. West, and Leona S. Aiken (2003), Applied Multiple Regression/Correlation Analysis for the Behavioral Sciences, Mahwah, NJ: Erlbaum.

Csikszentmihalyi, Mihaly, and Reed Larson (1987), "Validity and Reliability of the Experience-Sampling Method," Journal of Nervous and Mental Disease, 175 (9), 526-36.

David, James P., Peter J. Green, Rene Martin, and Jerry Suls (1997), “Differential Roles of Neuroticism, Extraversion, and Event Desirability for 
Mood in Daily Life: An Integrative Model of Top-Down and Bottom-Up Influences," Journal of Personality and Social Psychology, 73 (1), 149 59.

DeLongis, Anita, James C. Coyne, Gayle Dakof, Susan Folkman, and Richard S. Lazarus (1982), "Relationship of Daily Hassles, Uplifts, and Major Life Events to Health Status," Health Psvchologv, 1 (2), 119-36.

DeLongis, Anita, Susan Folkman, and Richard S. Lazarus (1988), "The Impact of Daily Stress on Health and Mood: Psychological and Social Resources as Mediators," Journal of Personality and Social Psychology, 54 (3), 486-95.

Elliot, Andrew J., and Todd M. Thrash (2002), "Approach-Avoidance Motivation in Personality: Approach and Avoidance Temperaments and Goals," Journal of Personality and Social Psychology, 82 (5), 804-18.

Enders, Craig K., and Davood Tofighi (2007), "Centering Predictor Variables in Cross-Sectional Multilevel Models: A New Look at an Old Issue," $\underline{\text { Psvchological Methods, }} 12$ (2), 121-38.

Folkman, Susan, and Judith T. Moskowitz (2000), "Positive Affect and the Other Side of Coping," American Psychologist, 55 (6), 647-54.

Fredrickson, Barbara L, (1998) "What Good Are Positive Emotions?" Review of General Psychology, 2 (3), 300-319.

Fredrickson, Barbara L., and Robert W. Levenson (1998), "Positive Emotions Speed Recovery from the Cardiovascular Sequelae of Negative Emotions," Cognition and Emotion 12 (2), 191-220.

Goodman, Elizabeth, Nancy E. Adler, Ichiro Kawachi, A. Lindsay Frazier, Bin Huang, and Graham A. Colditz (2001), "Adolescents' Perceptions of Social Status: Development and Evaluation of a New Indicator," Pediatrics, 108 (2), 1-8.

Hektner, Joel M., Jennifer A. Schmidt, and Mihaly Csikszentmihalyi (2006), Experience Sampling Method: Measuring the Quality of Everyday Life, Thousand Oaks, CA: Sage.

Hofmann, Wilhelm, Roy F. Baumeister, Georg Förster, and Kathleen D. Vohs (2012), "Everyday Temptations: An Experience Sampling Study of Desire, Conflict, and Self-Control," Journal of Personality and Social Psvchology, 102 (6), 1318-35.

Hofmann, Wilhelm, Eli J. Finkel, and Gráinne M. Fitzsimons (2015), “Close Relationships and Self-Regulation: How Relationship Satisfaction Facilitates Momentary Goal Pursuit," Journal of Personality and Social Psychologv, 109 (3), 434-52.

Hofmann, Wilhelm, and Paresh V. Patel (2015), "SurveySignal: A Convenient Solution for Experience Sampling Research Using Participants' Own Smartphones," Social Science Computer Review, 33 (2), 235-53.

Hofmann, Wilhelm, Daniel C. Wisneski, Mark J. Brandt, and Linda J. Skitka (2014), "Morality in Everyday Life," Science, 345 (6202), 1340-43.

Hox, Joop J. (2010), Multilevel Analysis: Techniques and Applications, 2nd ed., New York: Routledge.

Ivancevich, John M. (1986), "Life Events and Hassles as Predictors of Health Symptoms, Job Performance, and Absenteeism," Journal of Occupational Behavior, 7 (1), 39-51.

Kanner, Allen D., James C. Coyne, Catherine Schaefer, and Richard S. Lazarus (1981), "Comparison of Two Modes of Stress Measurement: Daily Hassles and Uplifts versus Major Life Events," Journal of Behavioral Medicine, 4 (1), 1-39.

Kanner, Allen D., S. Shirley Feldman, Daniel A. Weinberger, and Martin E. Ford (1987), "Uplifts, Hassles, and Adaptational Outcomes in Early Adolescents," Journal of Earlv Adolescence, 7 (4), 371-94.

Langston, Christopher A. (1994), "Capitalizing on and Coping with DailyLife Events: Expressive Responses to Positive Events," Journal of Personality and Social Psychology, 67 (6), 1112-25.
Laran, Juliano (2016), "Consumer Goal Pursuit," Current Opinion in Psvchology, 10, 22-26.

Lazarus, Richard S. (1984), "Puzzles in the Study of Daily Hassles," Journal of Behavioral Medicine, 7 (4), 375-89.

Lazarus, Richard S., Allen D. Kanner, and Susan Folkman (1980), "Emotions: A Cognitive-Phenomenological Analysis," Theories of Emotion, 1, 189-217.

Lyubormirsky, Sonja (2001), "Why Are Some People Happier than Others? The Role of Cognitive and Motivational Processes in Well-Being," American Psychologist, 56 (3), 239-49.

Lyubomirsky, Sonja, Kennon M. Sheldon, and David Schkade (2005), "Pursuing Happiness: The Architecture of Sustainable Change," Review of General Psychologv, 9 (2), 111-31.

Major, Brenda, Josephine M. Zubek, M. Lynne Cooper, Catherine Cozzarelli, and Caroline Richards (1997), "Mixed Messages: Implications of Social Conflict and Social Support within Close Relationships for Adjustment to a Stressful Life Event," Journal of Personality and Social Psvchology, 72 (6), 1349-63.

Mehl, Matthias R., and Tamlin S. Conner (2012), Handbook of Research Methods for Studying Daily Life, New York: Guilford.

Monroe, Scott M. (1983), "Major and Minor Life Events as Predictors of Psychological Distress: Further Issues and Findings," Journal of Behavioral Medicine, 6 (2), 189-205.

Müller, Dominique, Charles M. Judd, and Vincent Y. Yzerbyt (2005), "When Moderation Is Mediated and Mediation Is Moderated," Journal of Personality and Social Psychology, 89 (6), 852-63.

Raghunathan, Rajagopal, and Yaacov Trope (2002), "Walking the Tightrope between Feeling Good and Being Accurate: Mood as a Resource in Processing Persuasive Messages," Journal of Personalitv and Social Psychology, 83 (3), 510-25.

Repetti, Rena L. (1993) "Short-Term Effects of Occupational Stressors on Daily Mood and Health Complaints," Health Psychology, 12 (2), 125 31.

Seligman, Martin E. P. (2000), "Positive Psychology, Positive Prevention, and Positive Therapy," in Handbook of Positive Psychology, ed. Charles. R. Snyder and Shane J. Lopez, New York: Oxford University Press.

Stone, Arthur A. (1987), "Event Content in a Daily Survey Is Differentially Associated with Concurrent Mood," Journal of Personality and Social Psychology, 52 (1), 56-58.

Stone, Arthur A., and John M. Neale (1982), "Development of a Methodology for Assessing Daily Experiences," in Advances in Environmental Psychology: Environment and Health, ed. Andrew Baum and Jerome E. Singer, Hillsdale, NJ: Erlbaum.

Taquet, Maxime, Jordi Quoidbach, Yves-Alexandre de Montjoye, Martin Desseilles, and James J. Gross (2016), "Hedonism and the Choice of Everyday Activities," Proceedings of the National Academy of Sciences, forthcoming.

Taylor, Shelley E. (1991) "Asymmetrical Effects of Positive and Negative Events: The Mobilization-Minimization Hypothesis," Psychological Bulletin, 110 (1), 67-85.

Thomas, David L., and Ed Diener (1990), "Memory Accuracy in the Recall of Emotions," Journal of Personalitv and Social Psvchology, 59 (2), 29197.

Tice, Dianne M., Roy F. Baumeister, Dikla Shmueli, and Mark Muraven (2007), "Restoring the Self: Positive Affect Helps Improve SelfRegulation following Ego Depletion," Journal of Experimental Social Psychology, 43 (3), 379-84. 
Trope, Yaacov, Melissa Ferguson, and Raj Raghunathan (2000), "Mood as a Resource in Processing Self-Relevant Information," in Handbook of Affect and Social Cognition, ed. Joseph P. Forgas, Mahwah, NJ: Erlbaum, 256-74.

Trope, Yaacov, and Ayelet Fishbach (2000), "Counteractive Self-Control in Overcoming Temptation," Journal of Personality and Social Psychologv, 79 (4), 493-506.
Trope, Yaacov, and Efrat Neter (1994), "Reconciling Competing Motives in Self-Evaluation: The Role of Self-Control in Feedback Seeking,” Journal of Personality and Social Psychologv, 66 (4), 646-57.

Twenge, Jean M., Rhyne A. Sherman, and Sonja Lyubomirsky (2015), "More Happiness for Young People and Less for Mature Adults: Time Period Differences in Subjective Well-Being in the United States, 1972-2014," Social Psychological and Personality Science, 6 (1), 1-11. 


\section{University Library}

\section{- M M N E R VA A gateway to Melbourne's research publications}

Minerva Access is the Institutional Repository of The University of Melbourne

Author/s:

MEAD, N;Patrick, VM;Gunadi, MP;Hofmann, W

Title:

Simple pleasures, small annoyances, and goal progress in daily life

Date:

2016

Citation:

MEAD, N., Patrick, V. M., Gunadi, M. P. \& Hofmann, W. (2016). Simple pleasures, small annoyances, and goal progress in daily life. Journal of the Association for Consumer Research, 1 (4), pp.527-539. https://doi.org/10.1086/688287.

Persistent Link:

http://hdl.handle.net/11343/123276 